\title{
NUCLEAR POWER PLANTS: PRESENT, PAST, AND FUTURE
}

\section{Theos J. Thompson, Commissioner, U. S. Atomic Energy Commission}

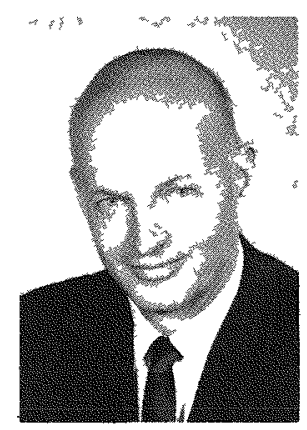

Dr Thompson received the A B. and A.M. degrees from the Untversity of Nebraska From 1942 to 1946 , he served in the U.S Army Chem1cal Warfare Service. From 1950 to 1952 , he worked and lectured at the University of California Radiation Laboratory at Berkeley, where he was awarded the Ph.D degree in nuclear physics. From 1952 to 1955 he was a Staff Assistant at Los Alamos from where he went to the Massachusetts Institute of Technology as Associate Professor of Nuclear Engmeering. He was in charge of dismantling "Clementine," the world's first fast reactor, a ploneering effort which showed that even a highly contaminated reactor could be dismantled safely. In 1958 he became Professor of Nuclear Engineering and Director of the M.I T Nucledr Redctor Facilty. He was serving in this capacity when President Nixon nominated him as Commissioner of the AEC. Dr. Thompson served as a consultant to the nuclear power industry, as a member and Charman of the AEC's Advisory Committee on Reactor Safeguards, and as a member of $\mathrm{U}$ S. delegations to international conferences. He received the AEC's Ernest O Lawrence Memorial Award in 1964 for his leadership in developing safer and economical nuclear reactors and for his inspired teaching. In March 1970 he recelved the Distinguished Service Award in Engineering at the University of Missouri at Rolla. Dr. Thompson died in an arplane accident on Nov 25, 1970.

I will try to give you some perspective on the environmental impact of nuclear power plants To do this I will have to start by discussing the total energy situation in the United States and then go on into the specifics on nuclear power plants, covering thermal effects and the rationale of radiation standards as they are applied by the 


\section{DISCLAIMER}

Portions of this document may be illegible in electronic image products. Images are produced from the best available original document. 
AEC Also I hope to be able to show you that we need to develop sources of fuel other than fossil fuels if we are to have any chance of preserving our way of life

We all have to recognize the basic factors involved in man's use of energy and man's need for energy I am sure that you all understand that the use of energy in the United States, as well as in other heavily industrialized countries, is woven inextricably into the basic fabric of our society Without energy, it is likely that many of us here would never have been born or survived because, among other things, there would be insufficient farm machinery, fertilizers, and means of distribution to provide the food necessary to sustain our current level of population The avalabiluty of energy has had a profound effect on man's recent past It will clearly exert even more of an influence on his future

Figure 1 shows the growth of the world's population from the birth of Christ to the present It took 16 centuries for the world's population to double from about one-quarter of a billion people to about one-half a billion people These people lived in a very rudimentary, largely self-sufficient, cottage economy The current doubling time on a world basis is about 35 years, and this accounts for the projection of about 7 billion people in the world by the year 2000 Whether it is the cause or an effect, an even sharper rise in energy utilization has accompanied the rise in population The U S electrical energy consumption is doubling every 10 years to provide for our growing population and to help raise our standard of living

In Fig 2 this population-growth curve is combined with a fossi-energy-use curve by the eminent geologist M King Hubbert One way to explain the interaction is to say that, as the energy from fossl fuels became avalable to man, population began to grow because individuals now had the wherewithal to produce more food than they could consume Figure 2 also makes clear that there is a limit to our fossil-fuel resources, and it implies a dramatic reduction in our population and in our way of hife if alternate sources of energy are not found We must all realize that it took nature millions of years to make these fuels and that they are irreplaceable in mankind's time scale on earth To be more specific, it has been estimated that only 300-400 years of coal and 60-70 years of oll are the total resources of fuel avalable to all of us Clearly there will be some major changes in our way of life if our oll resources are depleted and if we can no longer use internal-combustion engines for our automobiles, arrplanes, trucks, buses, and tractors We will have to make fuel for moving machinery and transport vehicles from coal or use electric-powered vehicles We will still need o1l and grease for lubrication. We must remember, too, that the natural fossil-fuel resources provide the feed materials for chemical and plastic industries that are now vital to our civilization Our nation must clearly make a greater effort to ensure that these precious materials are used as wisely as possible for our future well-being

A further thought can be derived from an examination of Fig 2 You are all aware of the seriousness of the arr-pollution problem we are facing because of the combustion of fossil fuels The area under the energy-use curve represents the total energy avalable to man from fossil fuels The shaded area under the curve represents 


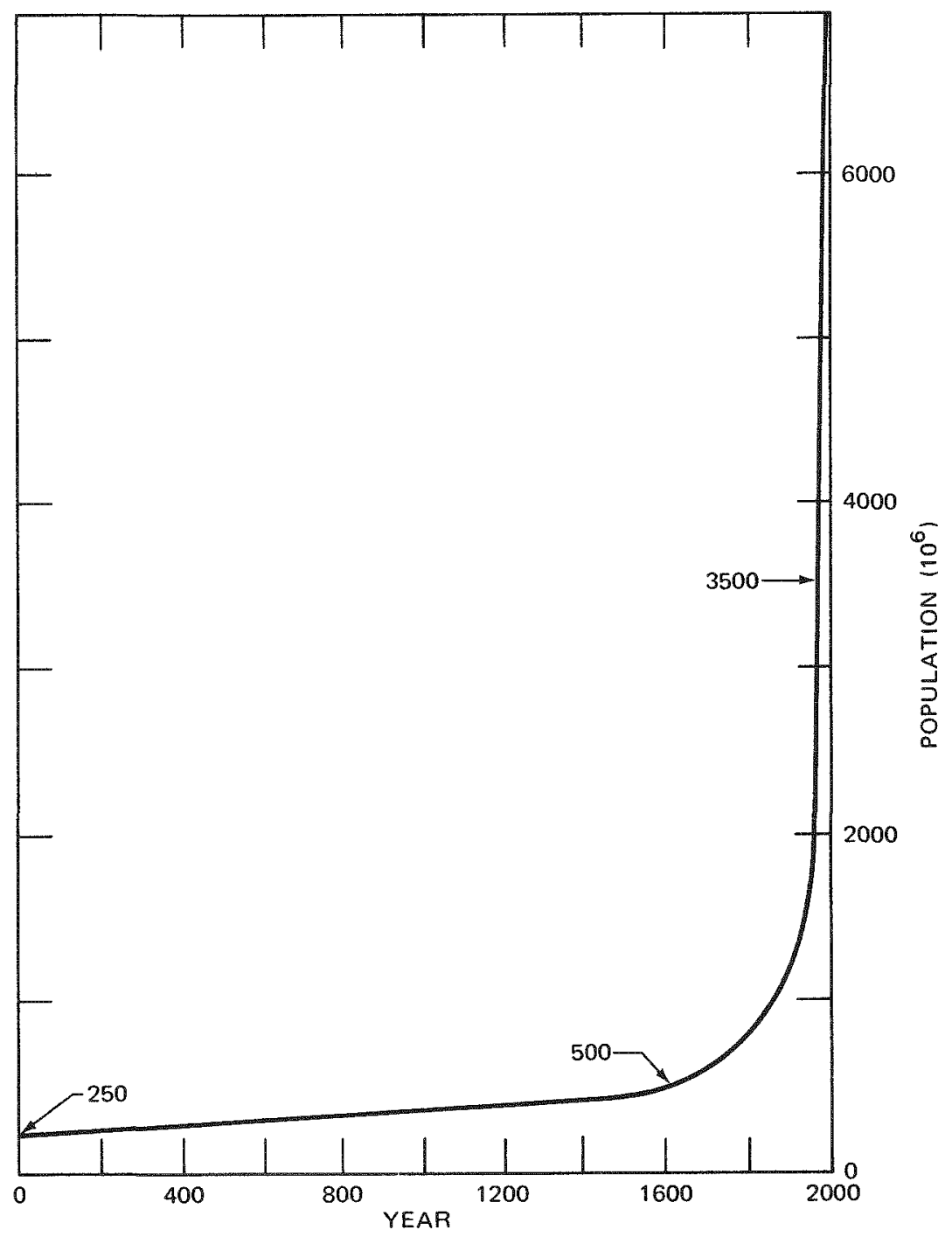

Fig. 1 World population.

that very small percentage of the total which has been used to date If at this level we already have serrous ar-pollution problems, you can get some visual picture of what they might be in the future of course, our government and industry are now planning and taking actions to reduce the release of pollutants, but substantial questions remain as to whether the situation can be handled adequately, as I will discuss a little later

Again looking at a few more specifics, Fig 3 shows how the total energy usage in the United States has varied in the past and projects usage to the year 2000 Note 


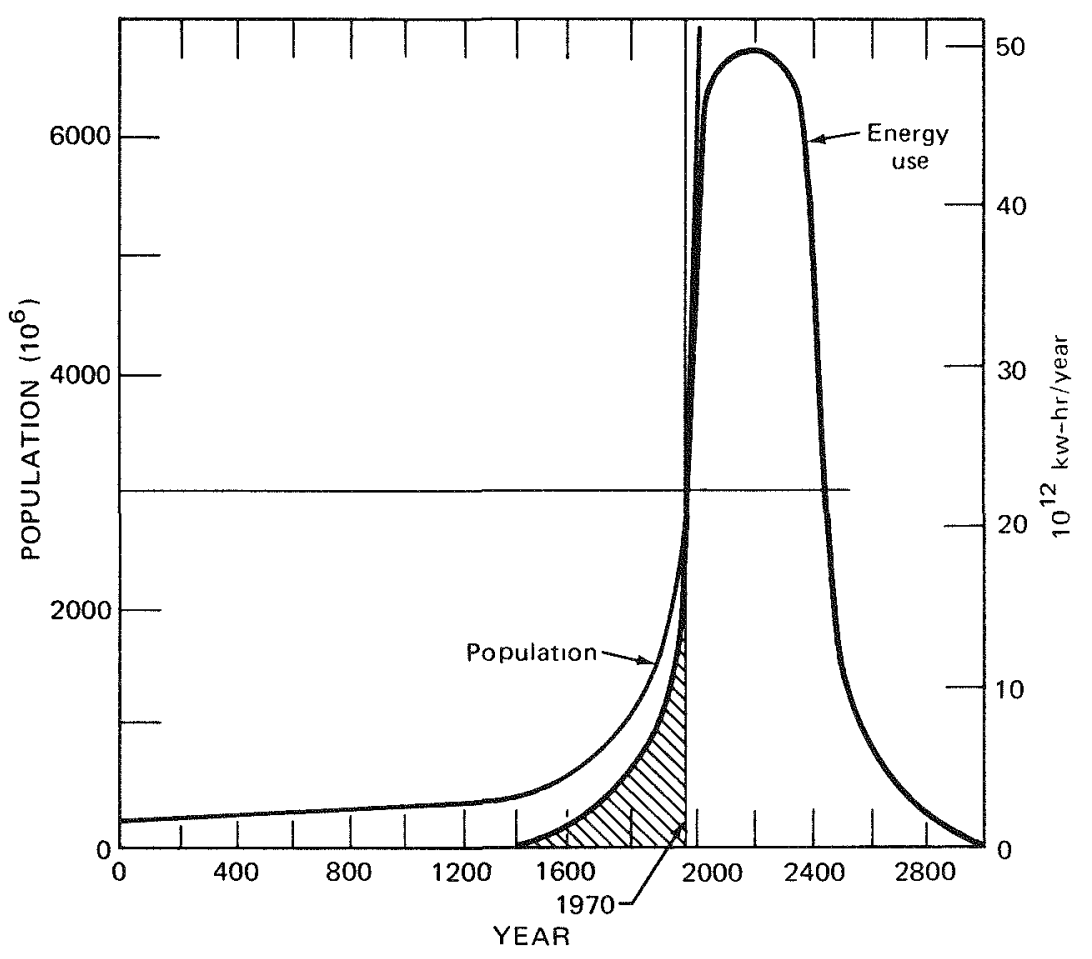

Fig 2 World population and energy use

that it is anticipated that coal will continue to increase gradually in total demand as the years go by in spite of the advent of nuclear power Oll is probably right now near its peak demand level domestically If nuclear power were not to be developed, there would have to be further increases in the use of fossil fuels up to the levels implied in Fig 2 Major changes in means of transportation will, of course, have a great effect on these predictions For instance, the development of a light, economic car battery would increase greatly the electrical energy used for transport and correspondingly might reduce the consumption of oll products for that purpose

By the year 2000 our current population of 200 million is expected to increase to about 300 million It is also expected that about $80 \%$ of these additional 100 million people will live close to existing centers of population This means that the bulk of the pollutants from the combustion of fossl fuels by these additional people will likely be released into areas where pollution levels are already quite high

Much of the literature currently being published, in my opinion, does not sufficiently emphasize the role of carbon dioxide as a pollutant Carbon dioxide acts as a blanket to hold in radiation from the sun more efficiently - the green house effect Consequently, the higher the percentage of $\mathrm{CO}_{2}$ in the atmosphere, the higher will be the temperature of the atmosphere If the amount of $\mathrm{CO}_{2}$ in the earth's atmosphere 


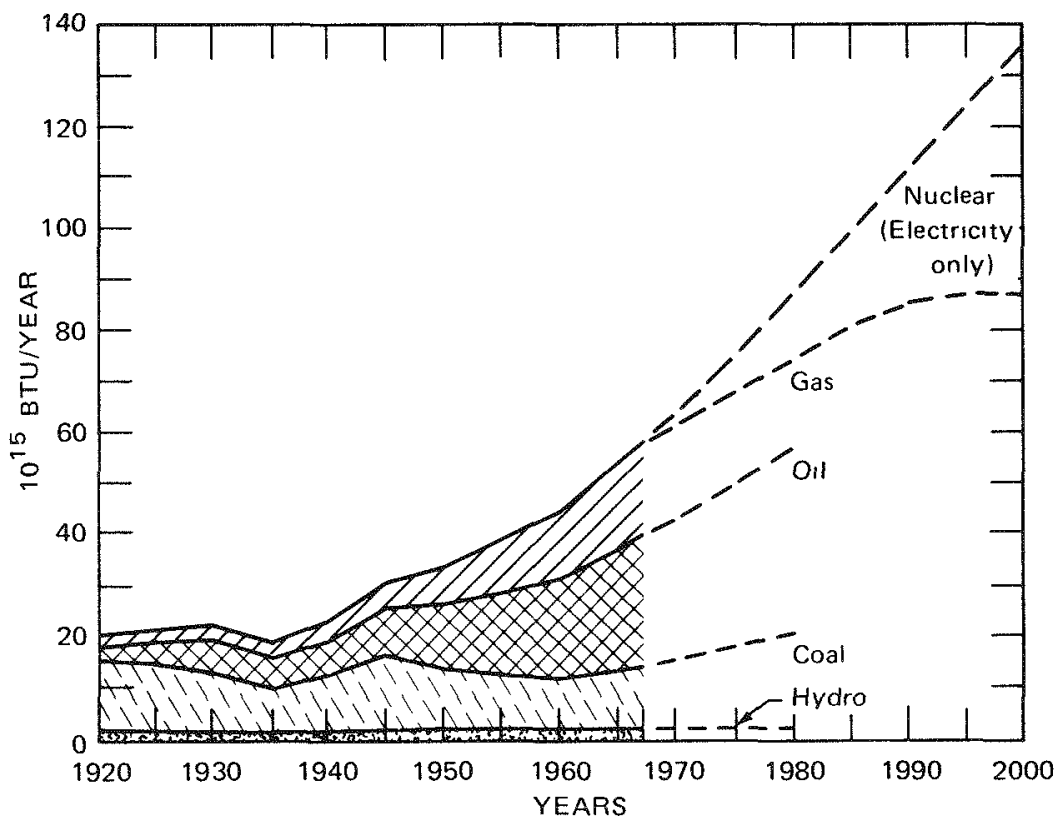

Fig. 3 United States energy consumption. (From Resources in America's Future, a spectal LMFBR study by the U. $S$ Bureau of Mines for the $\mathrm{AEC}$.)

rises from the current level of about 320 parts per million to about 400 parts per million by the year 2000 as predicted, the atmospheric temperature could be expected to increase about $3^{\circ} \mathrm{F}$ unless particulate matter suspended in the atmosphere is the dominant effect It is extremely difficult to extrapolate this temperature change and make any definitive estimates of what the effects of burning all our fossil fuels will be We could accelerate the coming of another ice age, or we could melt the polar ice caps which would inundate the coastal regions of the world Considerations such as these indicate that man, in his use of fossil fuels, is tampering with basic ecological cycles whose balance, if changed significantly, can have an environmental impact which is potentially more profound than those associated with the more commonly discussed air pollutants

Let us now examine the alternate forms of energy avallable Tidal energy, geothermal energy, and hydroelectric energy all represent feasible ways of generating power However, the total amounts of such energy which can be made avalable will at best fill only a small fraction of our needs Solar energy could supply all the energy we need However, its power density is extremely low, and it appears that its only feasible use in the next several decades will be on a small scale to supplement other sources of energy There is presently no practical way to utılize solar energy on a large scale, and none appears likely 
This leaves only two alternatives nuclear power from fission or fusion Nuclear power plants based on fission are economically avatlable now Controlled fusion is, however, as yet unproven even in the laboratory We have not yet reached the point with fusion which we had reached in 1942 with Fermi's fission pile Some in our laboratories say we will reach this goal in 10 years or less, others beheve it will not happen till the end of the century, still others say never My colleagues and I, however, believe that fusion will be successful, but, even after reaching the success of the Ferm1 pile stage, much engineermn development will be necessary In spite of fusion's great promise, we cannot afford to have our energy needs depend on a source which is unproven Fission breeder reactors have been proven to be feasible, and much engineering has been accomplished The next step is a demonstration commercial power plant We must get on with the breeder development and demonstration tasks Equally, we cannot neglect the research needs of our controlled fusion program

Present-day reactors - pressurized, bolling-water, and gas-cooled reactors - use the uranium-235 $\left({ }^{235} \mathrm{U}\right)$ 1sotope as fuel, and this isotope represents less than $1 \%$ of the naturally occurring uranium $W e$ are sure that there is sufficient ${ }^{235} \mathrm{U}$ avalable at current market prices to extend to about the year 2000 and to the year 2020 at about three times current fuel prices I have already referred to our need to develop breeder reactors Such a development will permit us to extend our nuclear-fuel resources The breeder reactor holds the key to providing a world rapidly growing in population and energy needs with an abundant and economic source of useful energy for perhaps a thousand years or more

What are the characteristics of a breeder-reactor system that will help fulfill the promises I have mentioned? A major one involves the efficient and economic use of fuel resources As mentioned, only a fraction of $1 \%$ of natural uranum is the fissionable ssotope ${ }^{235} \mathrm{U}$, the remainder $1{ }^{238} \mathrm{U}$ In the light-water converter-type reactors operating today, the uranum fuel used is enriched through the gaseousdiffusion process to contain about $4 \%$ of ${ }^{235} \mathrm{U}$ As fission of the ${ }^{235} \mathrm{U}$ occurs, a small fraction of the fertile ${ }^{238} \mathrm{U}$ is converted to plutonium $239\left({ }^{239} \mathrm{Pu}\right)$, and part of this plutonium is also consumed by fission Less than $5 \%$ of the total weight of fissle and fertile material in the core is fissioned before the core is removed from the reactor

To make efficient use of the great potential energy in all natural nuclear resources-the uranium and thorium abundant in nature, we must make use of the breeding principle Through this principle, involving the transmutation of fertile materials to fissionable materials $\left[{ }^{238} \mathrm{U}\right.$ to ${ }^{239} \mathrm{Pu}$ and thorium-232 $\left({ }^{232} \mathrm{Th}\right)$ to $\left.{ }^{233} \mathrm{U}\right]$, we can make use of essentially all the nuclear fuel in nature I should make clear at this point that two different breeder systems can be involved in this transmutation process The thermal breeder employing slow neutrons works best on the ${ }^{232} \mathrm{Th}-{ }^{233} \mathrm{U}$ cycle (called the thorium cycle for short), and the fast breeder--employing more energetic neutrons- operates on the ${ }^{238} \mathrm{U}-{ }^{239} \mathrm{Pu}$ cycle (called the uranium cycle) By taking full advantage of breeder reactors-by establishing safe and reliable breeder power systems - we could extend our use of the uranum and thonum reserves from decades to more than a thousand years 
Now let us examine the environmental impact of our current generation of water-cooled reactors Those of us who have been involved in bringing to fruition this new source of power believe in it and are proud to have played a part in its development At the same time we must tell you in all frankness that there are some disadvantages along with the advantages Although they completely eliminate any smoke, $\mathrm{SO}_{2}$, or $\mathrm{CO}_{2}$ discharges, these plants do add to already existing problems in our environment

Furst, these plants are not as thermally efficient as the best of the coal-or oll-fired plants Every plant that uses any type of fuel to heat water and make steam and drive an electrical turbine does so by generating heat at a high temperature and discharging heat at a low temperature The thermal efficiency of a plant is determined by a law of physics that cannot be violated, so far as we know This means that any device which converts heat to other forms of energy must in some way discharge waste heat to the environment About one-third more heat is discharged from a present-day nuclear plant to the environment than is discharged from the most efficient coal-or oll-fired plants This is one of the reasons why the Atomic Energy Commission is working hard to develop new types of reactors which will operate at higher temperatures-at least as high as the best of the conventional plants The new gas-cooled reactors, the liquid-metal-cooled fast breeder reactors, and the molten-salt reactors all have these high-thermal-efficiency characteristics Thus, you can clearly see one of our incentives for developing these new types of reactors is to reduce the thermal impact of nuclear power on the environment

You are, I am sure, all aware that all nuclear reactors add small amounts of radioactivity to the already existing radioactivity in man's environment You must also know, however, that mankind has lived since the beginning of time in a dilute sea of radioactivity It has always been so It will always be so One of the most serrous problems that the $\mathrm{AEC}$ faces in its public-information program is to explain radioactivity to the average citizen I would like to make another attempt this evening

Mankind receives radiation from a number of different natural and man-made sources Let us take the natural sources first In man's environment there are naturally occurring radioactive materials Within the body of man himself potassum- $40\left({ }^{40} \mathrm{~K}\right)$ is a natural radioactive isotope, inseparable biologically from the other potassium ssotopes which are absolutely vital for man's survival The radroactivity man carries with him in his body gives the average man hiving at sea level about one-fifth of the total radiation he receives All materials with which man comes in contact are radioactive to some degree The average man recelves about one-half of his naturally occurring radiation dose from his surroundings These doses vary somewhat For instance, a Wall Street banker who works in a granite building recerves more radiation than a housewife who lives in a suburban wooden house Man is bombarded continually by cosmic rays from outer space These cosmic rays cause radiation exposures to mankund The atmosphere provides a protective cloak for man Thus, a man living at sea level receives less radiation from cosmic rays than does a man living in Denver, Colo Almost one-third of the radiation that a man living at sea level receives 
comes from cosmic rays. If the same man lives in Denver, he may receive three times as much radiation from cosmic rays as he would in, say, New York City. In summary, the average man at sea level receives one-fifth of his naturally occurring radiation from sources in his own body, about one-half from his surroundings, and almost one-third from cosmic rays A man living in a normal seacoast environment with no special radioactive minerals around might receive about half as much total radiation as a man living in Denver If a jet pilot living in New York City were to fly twenty coast-to-coast round trips every year, he would receive as much radiation as a nonflyer who lived in Denver all year round. A Denver resident who recelves a chest $X$ ray receives an amount of rdiation which may ds much as double what he gets fiom natural background

Now let us put the radiation that one might recerve from the effluent discharges from a nuclear reactor into this picture of naturally occurring radioactivity. Operating experience has shown that the radiation one might receive by living in the near vicinity of a typical operating plant site for an entre year is equivalent to about what one would receive on a single round-trip, coast-to-coast airplane flight, which 1 about $1 / 20$ of the radiation one normally would receive in a year from natural sources at sea level or, in the case of Denver residents, perhaps $1 / 40$ of what one might receive by living in the "mile-high city" for a year Put another way, the extra amount of radiation that one might receive from this reactor by standing at the edge of the site would be equivalent to the extra amount of radiation that one might receive in the same year by living at the top of a 400 -ft hill rather than at the valley at its base Obviously, this is a very small amount of radiation compared with the levels which mankind has been receiving through all of the ages To date, in spite of many careful studies, no one has been able to detect any effect from these low levels of radiation, and it is unlikely that studies of hterally millions of cases would show any such effects In fact, the so-called "mega mouse" -one million mice-experiments carried out by Dr. Russell at the Oak Ridge National Laboratory are aımed at investigating this low-dose region as thoroughly as possible.

But you say, what then of the statements that have been made by Doctors Gofman and Tamplin regarding the possibility of deaths from cancer and leukemia Let me address myself to that topic

It is my understanding that the medical and statistical experts disagree with Dr Gofman in regard to a number of his hypotheses I shall not discuss these disagreements this evening since I am not an expert in the medical field I would like to point out, however, that the Fedeial Radiation Council (FRC) standards that form the basis for the AEC regulations are based on the assumption of no threshold for biological effects of iadiation, that is, that radiation effects are proportional to the dose received even at very low levels This is the same assumption used by Dr Gofman

More importantly, I believe that Dr. Gofman has not properly understood, or has chosen not to understand, the $\mathrm{AEC}$ regulations Under $\mathrm{AEC}$ regulations, should it appear that the dally intake of radioactive material from air, water, or food by a suitable sample of an exposed population group, averaged over a period not exceeding one year, would otherwise exceed 170 mrem/year (millirem per year), the AEC may 


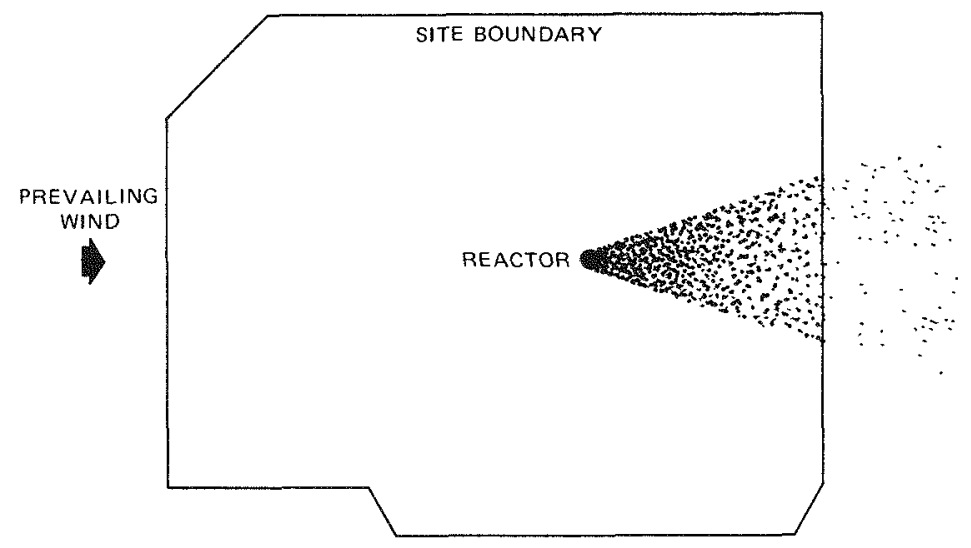

Fig. 4 Theoretical reactor site. Shaded area resprsents blue smoke.

limit quantities of radioactive materials released into air or water during a specified period of time. The intent here is clear. One must select a suitable sample from that segment of the population which can be defined as receiving the maximum amount of exposure. If, for instance, the radiation were to come from eating water lilies, which we will imagine for the moment are, for some strange reason, radioactive, then the suitable sample of the population would consist of those who regularly eat water lilies. The method then requires that the radiation dose to this water-lily eating segment of the population including all other nonnatural sources as well (except medical) be conservatively estimated. On the basis of these studies, limits would be set on the amount of radioactivity which might exist in water lilies by suitably restricting radioactive effluents in our stream. These water lilies are only imagined to be radioactive. I know of no radioactive water lilies.

Let me now discuss briefly how this principle is applied to reactor effluents. The $\mathrm{AEC}$ exercises its jurisdiction over reactor licensees by imposing limits on radioactivity in effluents which apply at the boundary of the restricted area. Although I wlll consider gaseous effluents in the example I am about to discuss, the same principles apply to liquid effluents.

Let us imagine that we have an irregularly shaped reactor site with a reactor located somewhere off center and a definite prevailing wind direction. Such a situation is shown in Fig. 4. The effluents from the site, both liquid and gaseous, are monitored as they leave the last control point. For instance, it is normal procedure to place in the stack of a reactor two monitors (one a backup) which transmit signals directly to continuously operating recorders to monitor the radioactivity level of effluent in the stack. It is not the concentration of radioactivity at the top of the stack that is important under the regulations, but rather the concentration of radioactivity at the site boundary. By the time the effluent reaches the site boundary, it is already much diluted by turbulent diffusion in the atmosphere. The concentration at the boundary is a calculated number that is predicted on the basis of conservative meteorological 
conditions including wind direction and weather conditions. The permissible maximum gaseous radioactivity discharge levels are estabhshed by working backwards through the conservative meteorological conditions and the permissible radiation levels at the site boundary to the equivalent amount of stack effluent passing the monitoring point. Measurements carried out at actual reactor sites indicate that the meteorological conditions and the calculational methods used are conservative by a factor of 2 or 3 and thus serve as an additional safety factor

At the present time safety-analysis reports calculate these effluent discharge rates from gaseous effluents on the basis of not exceeding $500 \mathrm{mrem} / \mathrm{year}$ to an individual located in the most exposed position at the edge of the site $24 \mathrm{hr}$ a day, 365 days a year. The FRC guidance covers both a maximum exposure for a single individual and also the 170-mrem/year exposure (which is about one-third of the $500-\mathrm{mrem}$ exposure) for a suitable sample of the population. The 170-mrem radiation level is about what the average citizen of Denver receives annually from natural causes. In this way protection is afforded for every individual as well as for the most exposed segment of the population. Both methods of looking at the radiation exposure limits are used by the AEC, but normally only that dealing with the individual is reported in safety-analysis reports. Since Dr. Gofman has talked about the total-population dosage rate, I will confine my remarks to exposure levels of $170 \mathrm{mrem} / \mathrm{year}$.

I hope that I have made it clear that under AEC regulations no suitable sample population in the United States can be exposed to more than 170 mrem/year in the limit, and no individual can be exposed to more than $500 \mathrm{mrem} / \mathrm{year}$.

For a reactor, individual exposure limits apply to persons assumed to be at the reactor boundary or in the most exposed condition It is clear that as the effluent gas moves out from the stack it becomes more and more dilute by diffusion in the atmosphere If we imagine that the effluent radioactivity might be blue smoke, it fades gradually until it becomes completely undetectable and unnoticeable as does smoke from any smoke stack

Dr. Gofman assumes that every person in the United States somehow recerves the limiting $170 \mathrm{mrem} /$ year. Under the assumptions of Dr. Gofman, the same color of smoke which is observed at the edge of the boundary must now, in some miraculous way, spread out and cover the entire United States, as is indicated in Fig. 5. Obviously, that cannot physically occur. Since we know from physical observation that smoke becomes more and more dilute, we can be assured that any radioactivity in the arr leaving the site will also become more and more dilute as it moves farther and farther away from the site. Thus, it is clear that Dr Gofman is wrong, and wrong by a large factor. Under his assumption, the entire country would be covered with, if you will, a rather dense blue smoke, as shown by the shaded area in Fig. 6. Obviously, this is not physically possible.

It becomes more difficult to make accurate estimates of how far he 1 wrong If one takes the Indian Point site and estimates the total radiation dose that could be given to the surrounding population by the Indian Point reactor site, one finds that the average dose to the population within 15 miles of the reactor site $1 \mathrm{~s}$ about $1 \%$ of the radiation levels that exist at the site boundary. Thus, even if the radiation level at the 


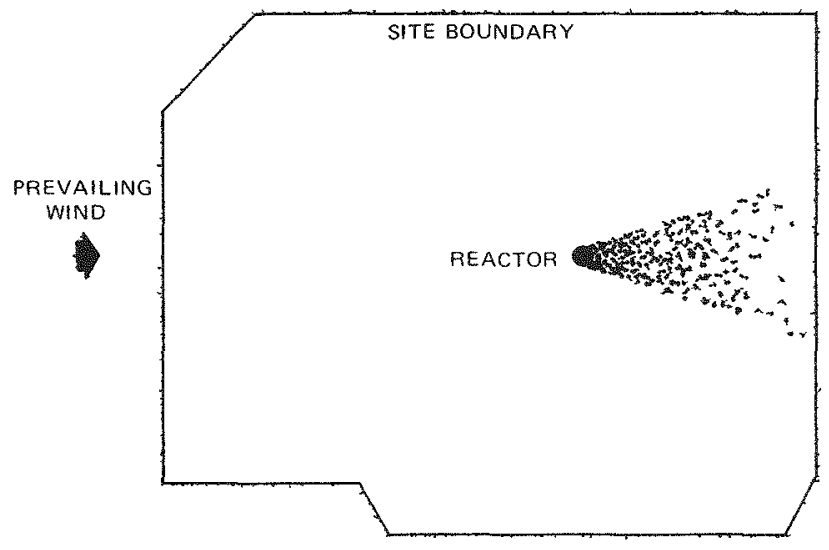

Fig 5 Illustration of the illogical assumption of undiluted distribu thon of blue smoke from reactor boundary

Indian Point site boundary were $500 \mathrm{mrem} /$ year, the average person living within 15 miles of the site would be unlikely to receive more than 5 mrem/year if he stayed out of doors fully exposed all year long I hope that helps to put these numbers in perspective When one considers the entire country then, the sort of schematic picture we actually have is shown in Fig 7 Here each of the reactor sites in the United States is shown surrounded by a 15 -mile circle Further studies on 11 different power reactor sites show that the resultant average dose rate for the whole population out to a 50-mile radus is $1 \mathrm{mrem} /$ year-or $1 / 500$ of the dose rate assumed to be at the site boundary In addition, experience with power reactors has shown that their discharge effluents are much lower than the AEC limits It is estimated that the average exposure to the total population living within a radius of 50 miles of the 13 nuclear plants operating in 1969 was less than $1 / 10_{00}(001)$ of 1 mrem or less than $1 / 17000$ of the 170 $\mathrm{mrem} /$ year limit

On occasion Dr Gofman has sald that there might be as many as 32000 extra cases of leukemia and cancer per year if the radioactivity in effluents were allowed to reach the maximum permissible levels under AEC regulations I hope that this discussion will show clearly that the numbers he uses do not represent the real world Instead of having 32000 cases per year, we probably have statıstically less than one extra case of cancer or leukemıa as a result of the presence of those nuclear reactors now in operation, under construction, or definitely planned 


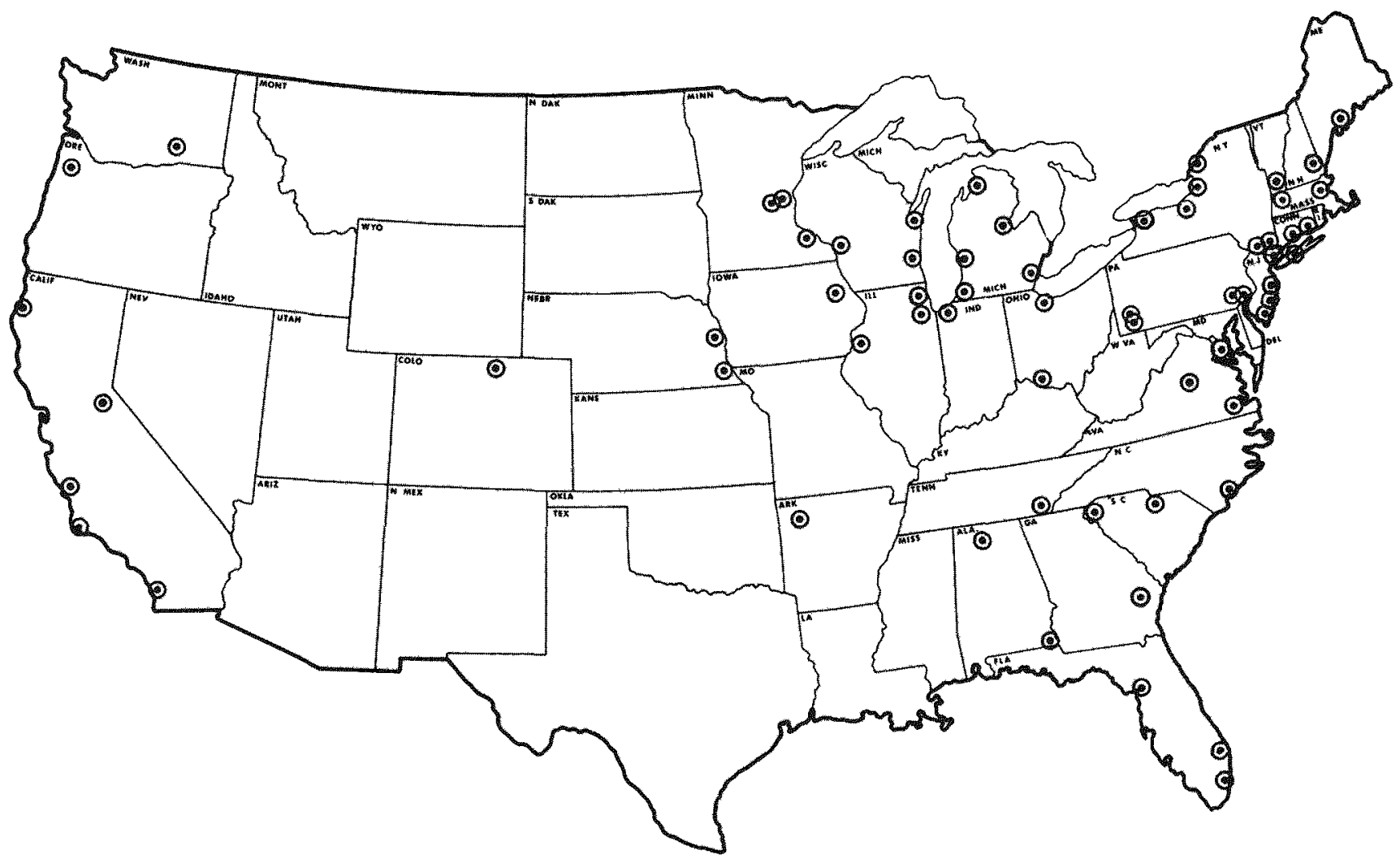

Fig. 6 Illustration of the illogical assumption of undiluted distribution of blue smoke over the entire United States. 


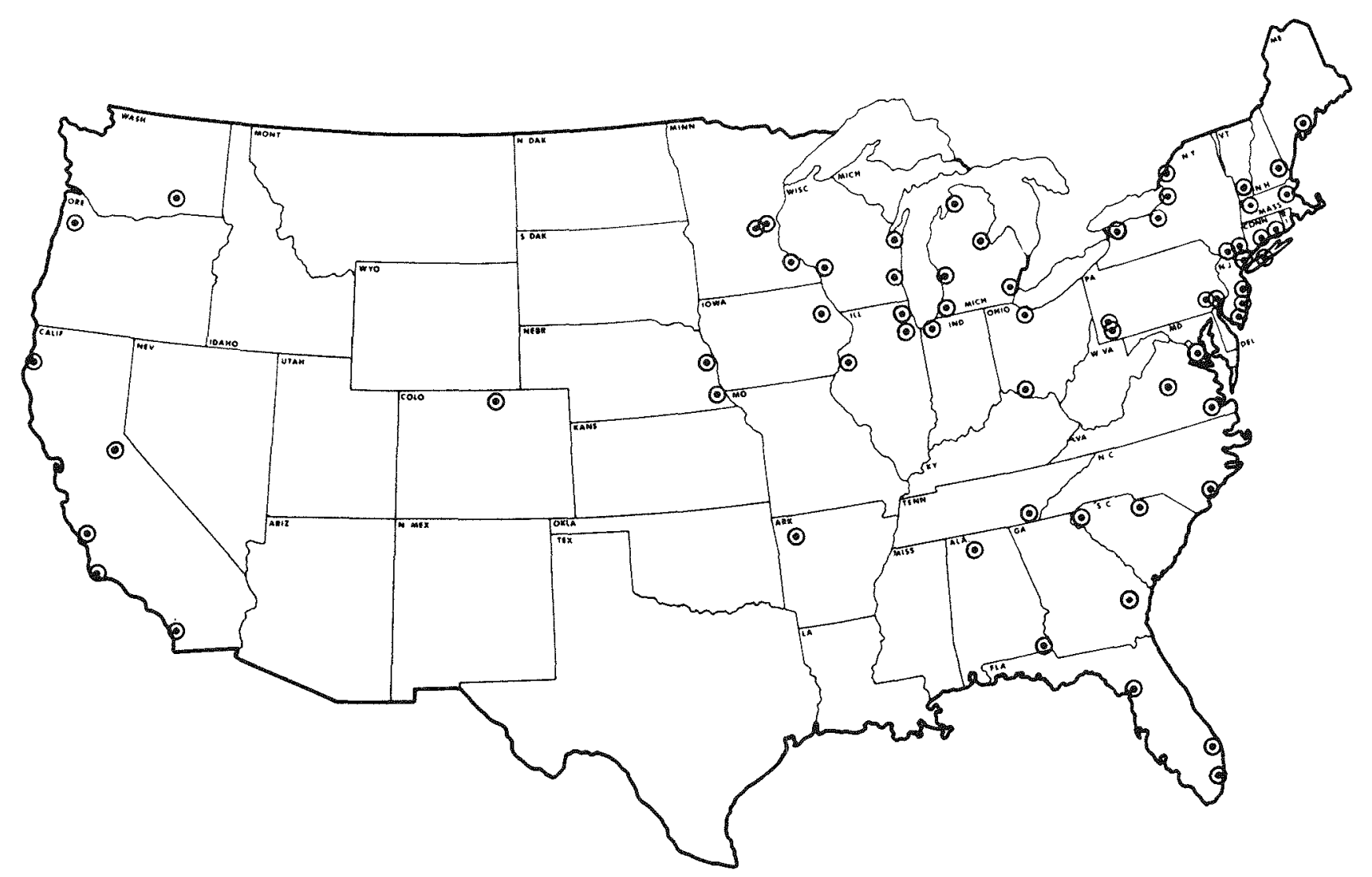

$z$
$\vdots$
0
0
0
0
0
0
0
0
0
0
0
0

Fig. 7 United States reactor sites shown within circles with a 15 -mile radius. Fifteen miles from the reactor site, radiation levels are about $1 \%$ of those at the site boundary. 
One should contrast these small effects with the situation in regard to coal fumes and smog to put the situation in balance In London, England, in December 1952, 4000 people passed away within 10 days because of air contamination caused by a combination of coal smoke and bad weather conditions Even though such large numbers of people as this are not likely to be directly killed by coal smoke, the cancer-causing effects of coal smoke and organic compounds contaned in smog and in automobile exhausts may, in a place such as Los Angeles, be simlar to those caused by smoking cigarettes Clearly, these effects of smog are of major proportions and are not even close to being fully understood or investigated

In fact, the AEC finds itself in the unusual position of being severely criticized because it has done a better job than almost anyone else in trying very hard to understand and evaluate the risks of radiation Radiation is understood much better than almost any other of the possible effects caused by man or his environment The presence of radioactive atoms as a contaminant can be detected with a sensitivity about one billion times that with which chemical contaminants can be detected It is strange that we who beheve that atomic energy is an improvement in our environmental situation find ourselves attacked on the environmental basis, when we know full well that when the final choice is made nuclear power must preval because the alternatives to nuclear power will have much worse effects on human health In the long run there appears to be no other source of power to support our civilization

It is probably worthwhle to mention an element called tritum Tritum is a heavy radioactive isotope of hydrogen produced in small quantities during the operation of nuclear reactors and has been cited as a source of public concern by some when considering the use of nuclear power It is necessary to put the quantity of tritium that could be involved in perspective There is not much of it Let me use an analogy Picture the entre Unted States as a huge forest having one tree on each square foot of land, each tree having 10,000 leaves Now, in this forest of a billion, billion leaves, if each leaf were to represent a hydrogen atom, there would also be dispersed throughout this forest about 80 tritium leaves due to cosmic rays and past nuclear weapons tests in the atmosphere The amount of tritum that would be added to the environment from the operation of all the nuclear reactors planned through the year 2000 would be equivalent to about one additional tritium leaf The nationwide forest of a billion, billion leaves would now contain about 81 tritium leaves

In addition to tritum some radioisotopes with special characteristics are, or may be, produced in reactors which should be mentioned The noble gases xenon and krypton are normally retaned within the fuel-element cladding during operation Since they are gases, they will be extracted from the fuel during reprocessing The AEC has developed in its laboratories several methods to collect and retain these gases As the reprocessing of fuel becomes more and more important, noble-gas-collection methods must be incorporated in the reprocessing Additionally, in reactors where fast neutrons bombard nitrogen, extremely small quantities of carbon-14 $\left({ }^{14} \mathrm{C}\right)$ could be found Other radioactive isotopes, fission products, or activation products are normally retained withn the fuel elements or water-purfication systems durng 
operation and can be collected and stored safely by methods already developed by the AEC

As responsible citizens we must make balanced decisions in matters as difficult and complex as environmental pollution It is not adequate for the critics of nuclear power to point only to its weaknesses, nor is it adequate for the proponents of nuclear power to point only to the weaknesses of fossil plants We all have to evaluate the benefits that power brings to us and then decide what kinds of risks are involved in the various methods of power generation in order to make the proper choices We at the $\mathrm{AEC}$ have been doing this for years in regard to nuclear power and safety of the public, but perhaps our view has been, at tımes, too narrow We have tried very hard for many years and believe that we have well-developed and conscientiously applied methods of risk evaluation But we have not quantufied the benefits very well yet, and it is only lately that we have begun to examne nuclear power vs other forms of power on a risk-benefit basis with anything approaching the same degree of rigor The risks involved from the presence of $\mathrm{SO}_{2}, \mathrm{CO}_{2}$, oxides of nitrogen, and particulates are not at all well understood My own vew of this balance is that, although nuclear power is a clear front-runner on an environmental-impact basis, we will have to use all the types of fuel and energy generation avallable to us, and we will have to improve the environmental impact of each of these to preserve an adequate environment

On balance, I feel quite certain that nuclear power will stand up well now and in the foreseeable future as far as comparative risks to the environment are concerned If you think about it just a little, you will perceive that our civilization must have adequate power, and you will find that most of it goes not for electric toothbrushes but for industrial uses Even the gasoline pumps in our filling stations are dnven by electricity How shall we get this power? The decision is yours 